\title{
Variations in Glucose Test Ordering Practices by Diabetes Risk Factors
}

\author{
Florence J. Dallo, PhD, MPH, Susan C. Weller, PhD, and Alvah R. Cass, MD, SM
}

Although the American Diabetes Association ${ }^{1}$ and the US Preventive Services Task Force (USPSTF) ${ }^{2}$ recommend screening individuals with diabetes risk factors, approximately one third of diabetes cases remain undiagnosed. ${ }^{3}$ Because either set of guidelines would be effective in detecting new cases of type 2 diabetes mellitus (DM2), ${ }^{4}$ one explanation for why there are so many cases of undiagnosed cases of diabetes may be that screening guidelines are applied inconsistently. This study addresses this important issue in clinical practice by assessing physician recognition of diabetes risk factors based on ordering laboratory tests for patients described in clinical vignettes.

\section{Methods}

In a study conducted in the Department of Family Medicine at the University of Texas Medical Branch, Galveston, health care providers were presented with case descriptions that systematically varied well-known risk factors for diabetes ${ }^{1,2}$ and were asked to list any tests or procedures that they might recommend for each patient (case) at an annual health visit. A clinical case was created for each of the 11 risk factors; some additional cases had no risk factors. Responses including glucose tests were classified into 3 categories: a fasting plasma glucose (FPG), an oral glucose tolerance

This article was externally peer reviewed.

Submitted 5 October 2007; revised 13 December 2007; accepted 17 December 2007.

From the School of Public Health, University of Texas, Dallas (FJD); the Department of Preventive Medicine and Community Health (SCW) and the Department of Medicine (ARC), University of Texas Medical Branch, Galveston.

Funding: This work was supported by the University of Texas, School of Public Health (to FJD) and NSF Grant no. BCS-0108232 (to SCW) and the Department of Family Medicine (to ARC).

Conflict of interest: none declared.

Corresponding author: Florence J. Dallo, PhD, MPH, University of Texas, School of Public Health, Dallas Regional Campus, 6011 Harry Hines Blvd., V8.112, Dallas, TX 75390 (E-mail: Flora.Dallo@UTSouthwestern.edu). test, or a hemoglobin $\mathrm{A}_{1 \mathrm{C}}(\mathrm{A} 1 \mathrm{C})$; a random blood glucose/fingerstick; or a metabolic panel (including an FPG).

\section{Results}

Participants ( $\mathrm{n}=51)$ were $60.0 \%$ female, $47.3 \%$ white, $32.7 \%$ faculty, and $60.0 \%$ residents. The highest rates of testing occurred for patients with pre-diabetes or gestational diabetes $(96.1 \%$ and 90.2\%, respectively; see Table 1). Overall screening rates for hypertension and dyslipidemia were only $66.7 \%$ and $45.1 \%$, respectively, and screening rates were low $(15.7 \%)$ for cases without a risk factor. Differences in test ordering between faculty and residents were significant for several risk factors. Residents requested fewer FPG/oral glucose tolerance test /A1C tests and 2 to 3 times as many metabolic panel tests than faculty for patients with a history of hypertension, those of older age $(\geq 45)$, and minorites $(P<.05)$.

\section{Conclusions}

Overall, glucose test ordering does not seem to be in accordance with recommended screening guidelines. Risk factors (pre-diabetes or gestational diabetes) that may be indicators of early disease resulted in the highest glucose screening estimates. These risk factors were similar in that their vignettes contained phrases (ie, "gestational diabetes," "elevated blood sugars") that may "trigger" thinking about diabetes. Furthermore, approximately $20 \%$ and $8 \%$ of providers reported they would specifically order an A1C for patients with pre-diabetes and gestational diabetes, respectively. Therefore, it seems that the use of the A1C test is primarily for the follow-up of diabetes symptoms (for patients with a history of elevated glucose, for example), and less so for patients without symptoms. Having a first-degree relative with diabetes also was likely to trigger screening. This particular risk factor is well-known and contains the word 
Table 1. Faculty and Resident Test Ordering by Risk Factors $(\mathrm{n}=51)$

\begin{tabular}{|c|c|c|c|c|c|c|c|}
\hline \multirow[b]{2}{*}{ Risk Factor } & \multirow{2}{*}{$\begin{array}{c}\text { Any } \\
\text { Glucose } \\
\text { Test }\end{array}$} & \multicolumn{3}{|c|}{ Faculty } & \multicolumn{3}{|c|}{ Residents } \\
\hline & & FPG/OGTT/A1C & Panel & None & FPG/OGTT/A1C & Panel & None \\
\hline \multicolumn{8}{|l|}{ Possible indicators of early disease } \\
\hline History of pre-diabetes & 96.1 & 77.8 & 11.1 & 11.1 & 72.7 & 27.3 & 0 \\
\hline History of GDM & 90.2 & 72.2 & 16.7 & 11.1 & 69.7 & 21.2 & 9.1 \\
\hline \multicolumn{8}{|l|}{ USPSTF Indicators for Screening } \\
\hline History of hypertension* & 66.7 & 27.8 & 33.3 & 38.9 & 6.1 & 63.6 & 30.3 \\
\hline Dyslipidemia & 45.1 & 27.8 & 11.1 & 61.1 & 18.2 & 30.3 & 51.5 \\
\hline \multicolumn{8}{|l|}{ Other risk factors for diabetes } \\
\hline First-degree relative with diabetes & 84.3 & 61.1 & 22.2 & 16.7 & 57.6 & 27.3 & 15.2 \\
\hline Minority ethnicity* & 62.8 & 55.6 & 22.2 & 22.2 & 3.0 & 51.5 & 45.5 \\
\hline History of vascular disease & 58.8 & 27.8 & 33.3 & 38.9 & 9.1 & 48.5 & 42.4 \\
\hline Sedentary lifestyle & 45.1 & 16.7 & 16.7 & 66.7 & 9.1 & 42.4 & 48.5 \\
\hline Overweight (BMI $\geq 25 \mathrm{~kg} / \mathrm{m}^{2}$ ) & 45.1 & 33.3 & 11.1 & 55.6 & 18.2 & 27.3 & 54.6 \\
\hline Age $\geq 45^{\star}$ & 41.2 & 27.8 & 11.1 & 61.1 & 3.0 & 39.4 & 57.6 \\
\hline PCOS & 39.2 & 27.8 & 11.1 & 61.1 & 15.2 & 24.2 & 60.6 \\
\hline No known diabetes risk factors & 15.7 & 5.6 & 7.4 & 88.9 & 3.0 & 16.2 & 81.8 \\
\hline
\end{tabular}

Values in table represent percentages. ${ }^{*} P<.05$, a comparison of the faculty versus resident percentages for FPG/OGTT/A1C, metabolic panel, and none.

FPG, fasting plasma glucose; OGTT, oral glucose tolerance test; A1C, hemoglobin $\mathrm{A}_{1 \mathrm{C}}$; GDM, gestational diabetes; USPSTF, US Preventive Services Task Force; BMI, body mass index; PCOS, polycystic ovary syndrome.

"diabetes," but it is not a sensitive indicator of undiagnosed diabetes (sensitivity, 44\%) as is older age (sensitivity, $84 \%) .{ }^{4}$ Glucose testing for patients with hypertension or dyslipidemia as recommended by the USPSTF was low.

For most risk factors, residents ordered approximately twice as many panel tests as did faculty. It is unclear whether this difference is because of a more focused diagnostic approach by faculty or other factors. Studies show that the average number of tests ordered is a function of knowing the cost of the tests. ${ }^{5-8}$ Educational efforts (and continuing education) might focus not only on presenting (a) risk factors for the development of DM2, ${ }^{1,2}$ but also (b) their relative sensitivity for detecting new cases of $\mathrm{DM}_{2}{ }^{4}$ and (c) recommendations of the USPSTF to target cardiovascular risk factors, because of the link between diabetes and cardiovascular disease.

\section{References}

1. Expert Committee on the Diagnosis and Classification of Diabetes Mellitus. Report of the expert committee on the diagnosis and classification of diabetes mellitus. Diabetes Care 2003;26(Suppl 1):S5-S20.
2. US Department of Health and Human Services, Agency for Healthcare Research and Quality. Screening for diabetes mellitus, adult type 2. Available at http://www.ahrq.gov/clinic/uspstf/uspsdiab.htm. Accessed 4 December 2007.

3. Harris MI, Flegal KM, Cowie CC, et al. Prevalence of diabetes, impaired fasting glucose, and impaired glucose tolerance in US adults. The Third National Health and Nutrition Examination Survey, 19881994. Diabetes Care 1998;21:518-24.

4. Dallo FJ, Weller SC. Effectiveness of diabetes mellitus screening recommendations. Proc Natl Acad Sci USA 2003;100:10574-9,

5. Cummings KM, Frisof KB, Long MJ, et al. The effects of price information on physicians' test-ordering behavior. Med Care 1982;20:293-301.

6. Long MJ, Cummings KM, Frisof KB. The role of perceived price in physicians' demand for diagnostic tests. Med Care 1983;21:243-50.

7. Hampers LC, Cha S, Gutglass DJ, et al. The effect of price information on test-ordering behavior and patient outcomes in a pediatric emergency department. Pediatrics 1999;103:877-82.

8. Seguin P, Bleichner JP, Grolier J, et al. Effects of price information on test ordering in an intensive care unit. Intensive Care Med 2002;28:332-335. 